\title{
Technical Modifications for Patients with Aortic Stenosis and Calcified Ascending Aorta During Aortic Valve Replacement
}

\author{
Masanori Hirota, Joji Hoshino, Yasuhisa Fukada, Shintaro Katahira, \\ Taichi Kondo, Kenichi Muramatsu and Tadashi Isomura \\ Department of Cardiovascular Surgery, Hayama Heart Center, Kanagawa, \\ Japan
}

\section{Introduction}

Aortic stenosis (AS) is the most prevalent valvular heart disease in developed countries 1 ). Aortic valves deteriorate due to degenerative processes, and calcification is the most frequent cause of AS. Clinical factors related to aortic valve calcification are similar to those for atherosclerosis, and the prevalence of calcified aortic valves increases with age ${ }^{2}$. As a consequence, AS is associated with a high risk of cardiovascular morbidity and mortality in the elderly3). To achieve longer life expectancy, aortic valve replacement (AVR) is recommended as a definitive treatment for calcified aortic valves 4,5$)$. Although the operative mortality of isolated AVR is low, the surgical risk is increased in elderly patients due to concomitant procedures and/or comorbidities associated with advanced age6). Thus, it is very important to plan a careful strategy for co-existing atherosclerotic lesions, especially in the ascending aorta.

Atherosclerotic change in the ascending aorta is one of the potential causes of postoperative stroke, which results in higher morbidity and mortality7,8). Most embolic events are associated with manipulation of the ascending aorta such as the clamping of the ascending aorta or the release of aortic crossclamping9). To reduce embolic complications, surgical treatments have changed, and there are several techniques, including AVR during hypothermic circulatory arrest (HCA)10-12), complete thromboendarterectomy during $\mathrm{HCA}^{13)}$, endarterectomy or ascending aorta replacement during $\mathrm{HCA}^{14)}$, endoaortic balloon occlusion ${ }^{15)}$, and apicoaortic conduit ${ }^{16)}$. Despite aggressive attempts to deal with the calcified ascending aorta, surgical outcomes such as the stroke rate, morbidity, and mortality have remained unsatisfactory. This paper describes our surgical strategy for patients with AS associated with a diseased calcified ascending aorta. Furthermore, meticulous techniques for atherosclerotic lesions designed to avoid perioperative morbidity are described in detail.

\section{Patients and methods}

\subsection{Patients}

Between May 2000 and December 2009, 705 patients underwent AVR due to AS ( $n=447$ ) or aortic regurgitation $(n=268)$. Of the patients with AS, $46(11 \%)$ had a calcified ascending aorta. A calcified ascending aorta is defined on computed tomography (CT) as severe and 
extensive calcification, which would increase the risk of atheroembolic complications during operative procedures.

The patients were 25 males and 21 females, ranging between 44 and 93 years of age (mean, $73 \pm 10$ years). Hemodialysis was required in 6 patients $(13 \%)$ due to chronic renal failure. In this series, 10 patients $(22 \%)$ had a porcelain aorta (a totally calcified aorta). Although preoperative imaging obtained by $\mathrm{CT}$ revealed the extent and thickness of calcification of the ascending aorta, operative procedures were determined by intra-operative findings.

\subsection{Surgical technique}

\subsubsection{Preparation}

Under general cardiac anesthesia and monitoring, an 8-mm, gelatin-impregnated, woven Dacron graft (Gelweave; VASCUTEK $®$, a TERUMO company, Renfrewshire, UK) was sewn to the right axillary artery ${ }^{17)}$. After median sternotomy, cardiopulmonary bypass (CPB) was installed via the right axillary artery with single venous drainage. A pulmonary vein vent was used to prevent potentially damaging distension during ventricular fibrillation. The body was cooled to $28^{\circ} \mathrm{C}$ for internal inspection of the ascending aorta during brief circulatory arrest. Gentle palpation of the ascending aorta provided three-dimensional spatial imaging of the calcified aorta during cooling. Epiaortic echocardiography was also used to obtain intimal imaging of the ascending aorta along aortotomy.

\subsubsection{Brief circulatory arrest for internal inspection of the ascending aorta}

At a core body temperature of $28^{\circ} \mathrm{C}$, brief circulatory arrest was initiated to observe the intimal condition of the ascending aorta. The ascending aorta was opened at the optimal site, which was determined by gentle palpation and epiaortic echocardiography. An oblique (J-shaped) incision is usually used for AVR. When severe calcification involves the sinus of Valsalva, a longitudinal (I-shaped) incision or transection would be indicated (Fig. 1); a representative CT image of a calcified sinus of Valsalva is shown in Fig. 2. A severely calcified sinus of Valsalva prevents surgeons from obtaining a satisfactory surgical field around the aortic annulus, even if the anterior wall of the ascending aorta is retracted through the usual oblique incision. Moreover, prosthetic valves cannot be passed through a calcified sinus of Valsalva due to the limited diameter caused by nearly-circumferential calcification and the height of the prosthesis. For these reasons, it is very important to extend the I-shaped aortic incision to the sinus of Valsalva toward the commissure between the right and non-coronary cusps. After opening the ascending aorta, the intima was directly observed to confirm the existence of fragile debris. When the calcified ascending aorta was clampable at a safe site with just only calcification but no fragile debris, simple AVR was indicated. When there was severe calcification and no lesion for aortic crossclamping, both AVR and ascending aorta replacement were indicated during circulatory arrest with selective cerebral perfusion.

\subsubsection{Simple AVR}

The calcified ascending aorta was safely crossclamped after internal inspection of the ascending aorta during brief circulatory arrest at moderate hypothermia. Systemic perfusion was commenced via the right axillary artery after aortic crossclamping. Re-warming of the body was then started. Antegrade tepid blood cardioplegia was selectively delivered to obtain diastolic cardiac arrest. For maintenance, retrograde tepid blood cardioplegia was infused every 20 to 30 minutes. When remnant fragile debris was detected on the proximal ascending aorta, it was gently peeled as far as possible before AVR. 


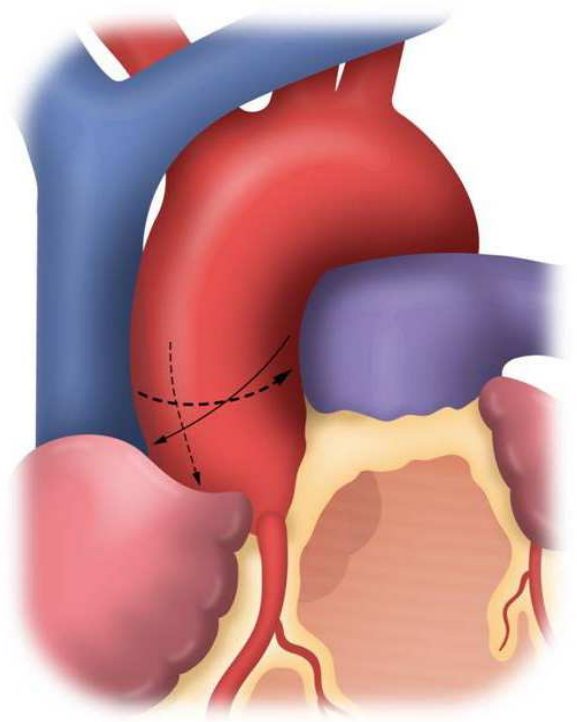

Fig. 1. A schema of the incisions of the ascending aorta for aortic valve replacement (AVR). There are three incision lines for aortotomy on the ascending aorta. The oblique (J-shaped) line for routine AVR is shown by the solid arrow. The horizontal or longitudinal (I-shaped) and transverse lines for patients with a calcified sinus of Valsalva are shown by dotted arrows. (Hirota et al.)

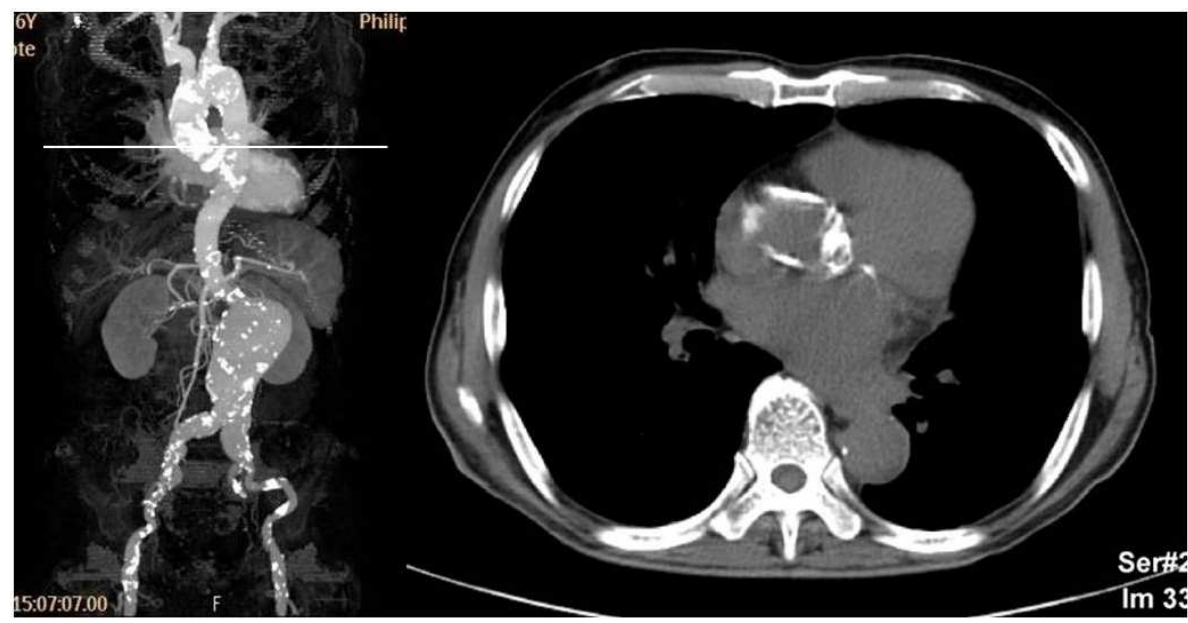

Fig. 2. On the left side, calcification of the aorta is shown by three-dimensional computed tomography (CT) images in a patient with a calcified sinus of Valsalva. On the right side, a representative image of a calcified sinus of Valsalva is obtained from the scanning level shown by a solid line on the three-dimensional CT. Nearly-circumferential calcification is detected on the sinus of Valsalva. (Hirota et al.) 
Firstly, the aortic valves were sharply removed, and one-quarter of gauze was placed into the left ventricle (LV) to catch calcific debris. Decalcification was gently performed with Pean Hemostatic Forceps and Selman Tissue Forceps (Pilling®; Teleflex Medical, Tuttlingen, Germany) around the aortic annulus. The LV cavity was carefully irrigated with copious amounts of cold saline to reduce the risk of emboli. Secondly, a 2-0 polyfilament braided non-everting mattress suture with spaghetti (Matsuda-ika Kogyo, Tokyo, Japan) was placed for each commissure. Great attention is needed for commissural suturing between the right and non-coronary cusps. Deep stitches for the commissure would injure the conduction system, which would result in complete atrioventricular block. For patients with this complication, permanent pacemaker implantation would be necessary. Subsequently, sizing of the prosthetic valve was performed in accordance with each commercial sizer. When a bioprosthetic valve was selected, it was irrigated with saline for preparation. Thirdly, intercommissural sutures were placed for each coronary cusp. Independent of the type of prosthetic valve, 15 sutures, one for each commissure and four for each coronary cusp, were usually placed (Fig. 3). Then, a total of 15 sutures was placed on the prosthetic annulus, and the appropriate valve was seated in the supravalvular position.

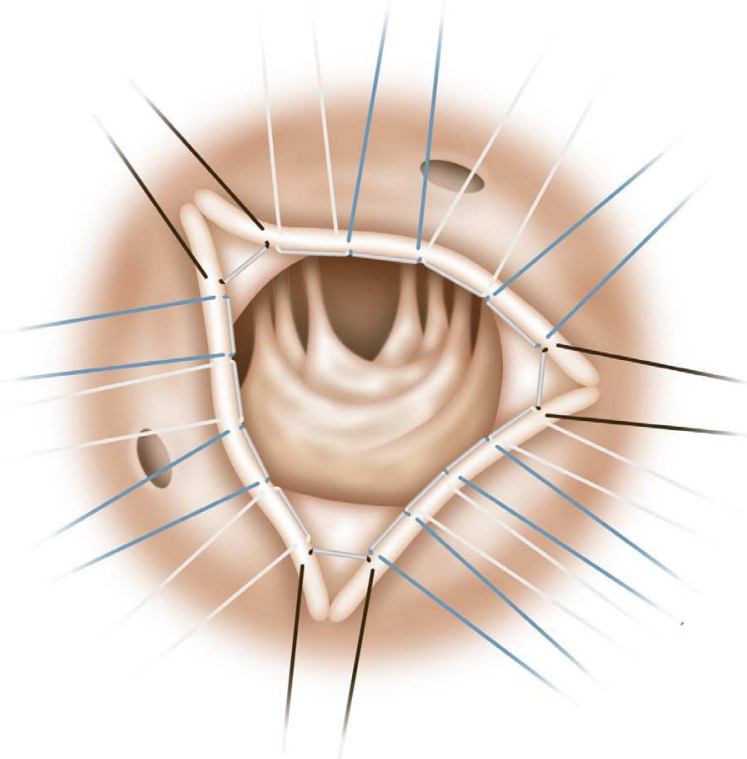

Fig. 3. Independent of the type of prosthetic valve, 15 2-0 polyfilament braided non-everting mattress sutures with spaghetti were usually placed for routine aortic valve replacement. Firstly, three black sutures were placed for each commissure. Secondly, four sutures, alternating white and blue, were placed for each coronary cusp. (Hirota et al.)

\subsubsection{Closure of a calcified ascending aorta}

For patients with a non-calcified aortic wall, the ascending aorta is usually closed with 5-0 polypropylene continuous horizontal mattress and over-and-over sutures. However, for patients with a fragile aortic wall, the aortotomy was closed with 4-0 polyfilament braided 


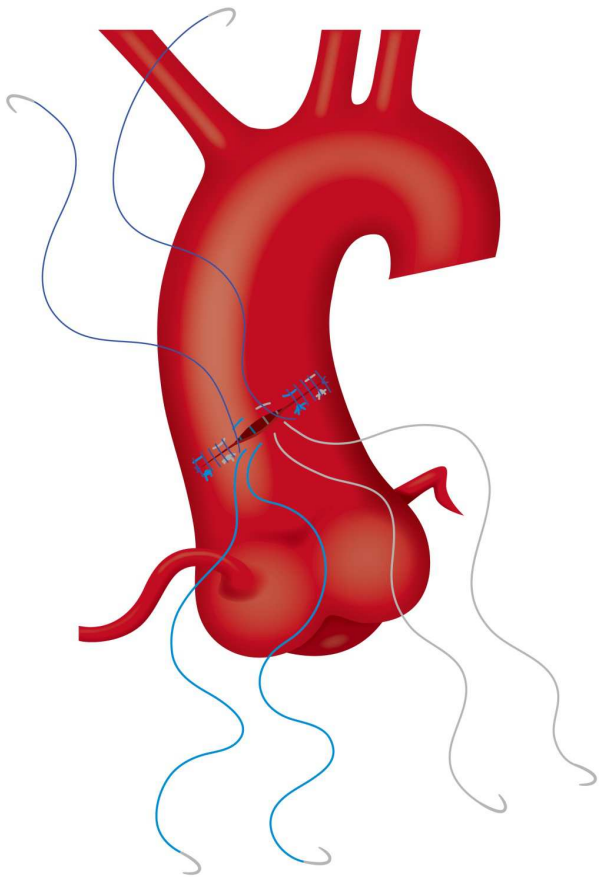

A

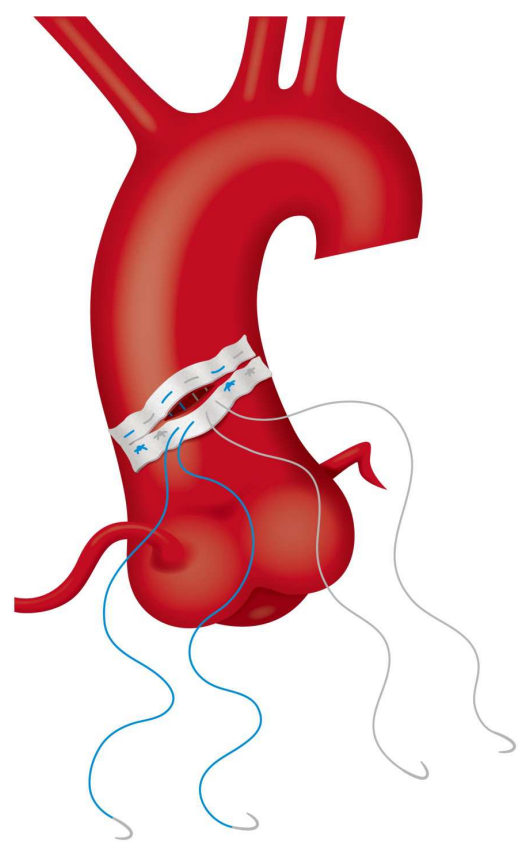

B 


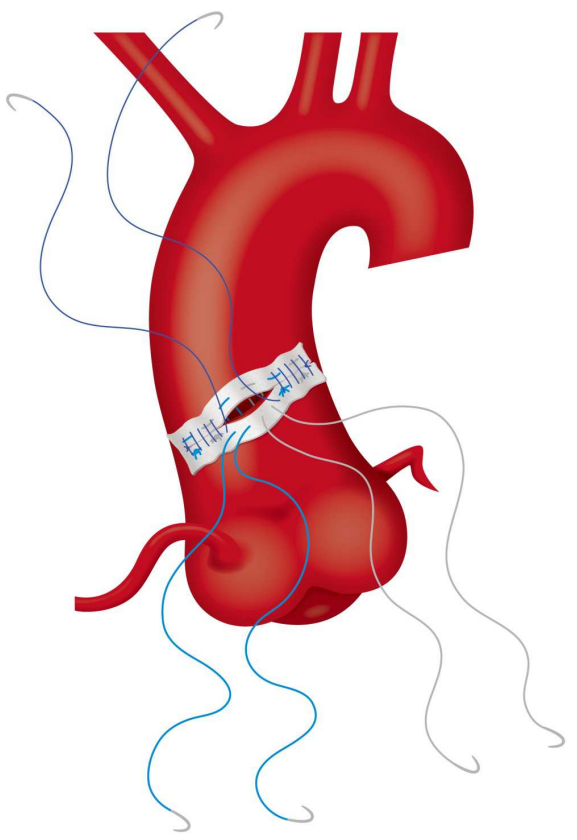

C

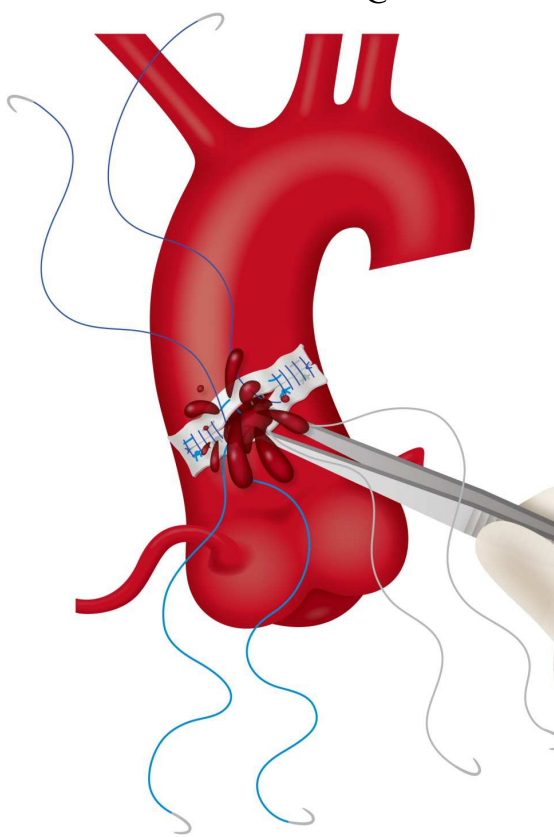

D

Fig. 4. 4A. For patients with a fragile aortic wall, the aortotomy was closed with 4-0 polyfilament braided horizontal mattress and 5-0 polypropylene over-and-over sutures. $\mathbf{4 B}$. 
For patients with a severely calcified aorta, a knitted polyester strip of $2 \mathrm{~cm}$ in width was placed over the aortotomy. It was fixed with 4-0 polyfilament braided horizontal mattress sutures. Except for the two central sutures, all sutures were tied down. 4C. Closure of the aortotomy was started with 5-0 polypropylene over-and-over sutures from both edges toward the central untied sutures. 4D. The aortotomy for the two untied sutures (about 2 $\mathrm{cm}$ in length) was kept open. Under low-flow cardiopulmonary bypass, the ascending aorta was carefully declamped to flush out remaining debris from the aortotomy for about 30 seconds. (Hirota et al.)

horizontal mattress (Matsuda-ika Kogyo, Tokyo, Japan) and 5-0 polypropylene over-andover sutures (Prolene ${ }^{\circledR}$; Ethicon, Somerville, NJ, USA) (Fig. 4A). When the edges of the aortotomy included calcification, an endarterectomy was performed to facilitate closure of the ascending aorta.

For patients with a severely calcified aorta, a knitted polyester strip of $2 \mathrm{~cm}$ in width (Sauvage Filamentous Fabric ${ }^{\circledR}$; Bard Peripheral Vascular Inc., Tempe, AZ, USA) was used to prevent cutting and injury of the calcified ascending aorta. The left end of the strip was divided to place over the aortotomy. At first, 4-0 polyfilament braided horizontal mattress sutures were required for both ends to fix the trimmed strip. Other horizontal mattress sutures were placed along the aortotomy. Except for the two central sutures, all sutures were tied down (Fig. 4B). Then, aortotomy closure was started with 5-0 polypropylene over-and-over sutures from both edges toward the central untied sutures (Fig. 4C). The aortotomy between the two untied sutures (about $2 \mathrm{~cm}$ in length) was kept open to flush out the debris. Under low CPB flow, the ascending aorta was carefully declamped with manual occlusion of the neck vessels. A sufficient amount of blood was flushed out from the aortotomy for about 30 seconds (Fig. 4D). Then, the two central sutures were tied down. The central portion of the aortotomy was reinforced with 5-0 polypropylene over-and-over suture.

\subsubsection{AVR plus ascending aorta replacement}

When simple AVR cannot be safely performed due to an unclampable ascending aorta, AVR plus ascending aorta replacement is selected for these patients. During circulatory arrest at a core body temperature of $28^{\circ} \mathrm{C}$, cerebral perfusion was selectively initiated. Antegrade tepid blood cardioplegia was selectively delivered to obtain cardioplegic cardiac arrest. For maintenance, retrograde tepid blood cardioplegia was infused every 20 to 30 minutes.

The ascending aorta was transected above the level of the sinotubular junction and subsequently transected below the level of the innominate artery. The prosthetic aortic valve was seated in the supravalvular position. The technical details of the AVR were described above. After seating the prosthetic valve, localized endarterectomy for the distal anastomosis was performed if needed. The distal end of the ascending aorta was encircled by a 2-cm-wide felt strip. A gelatin-impregnated, woven Dacron graft (J Graft SEALED NEO®; JUNKENMEDICAL Co., Japan Lifeline, Saitama, Japan) with one side branch was implanted as open distal anastomosis. It was sewn to the distal end of the ascending aorta with 4-0 polyfilament braided sutures in a horizontal mattress fashion (Fig. 5A). The distal end of the Dacron graft (1 $\mathrm{cm}$ in length) was gently fixed in an inverted form (Fig. 5B). Then, the anastomosis was reinforced with additional 3-0 polypropylene over-and-over suture (Fig. 5C). After completion of the distal anastomosis, cerebral perfusion was withdrawn, and antegrade systemic perfusion was started via the side branch of the Dacron graft (Fig. 5D). 


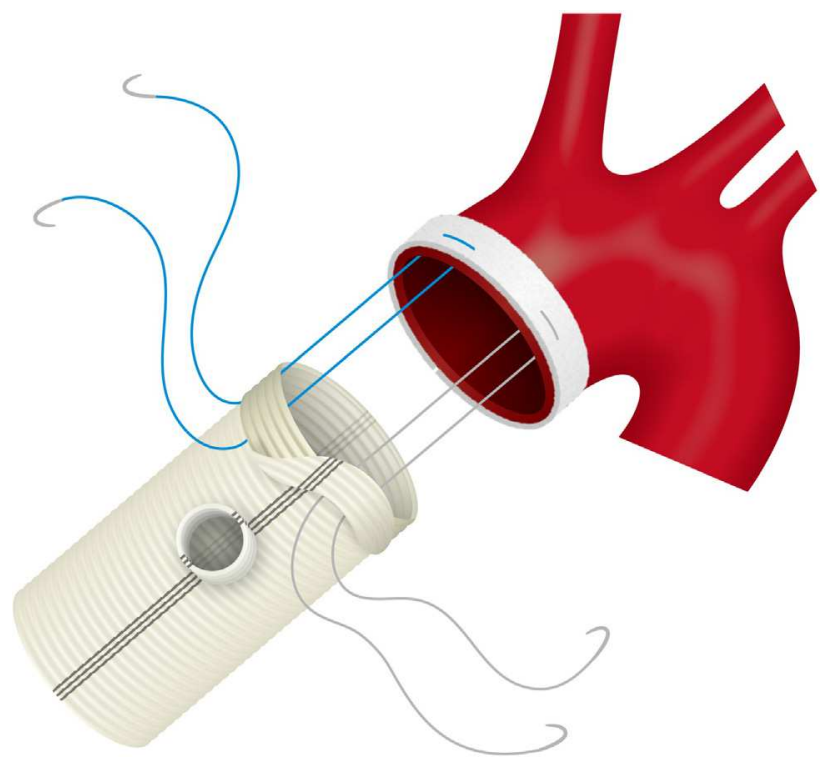

A

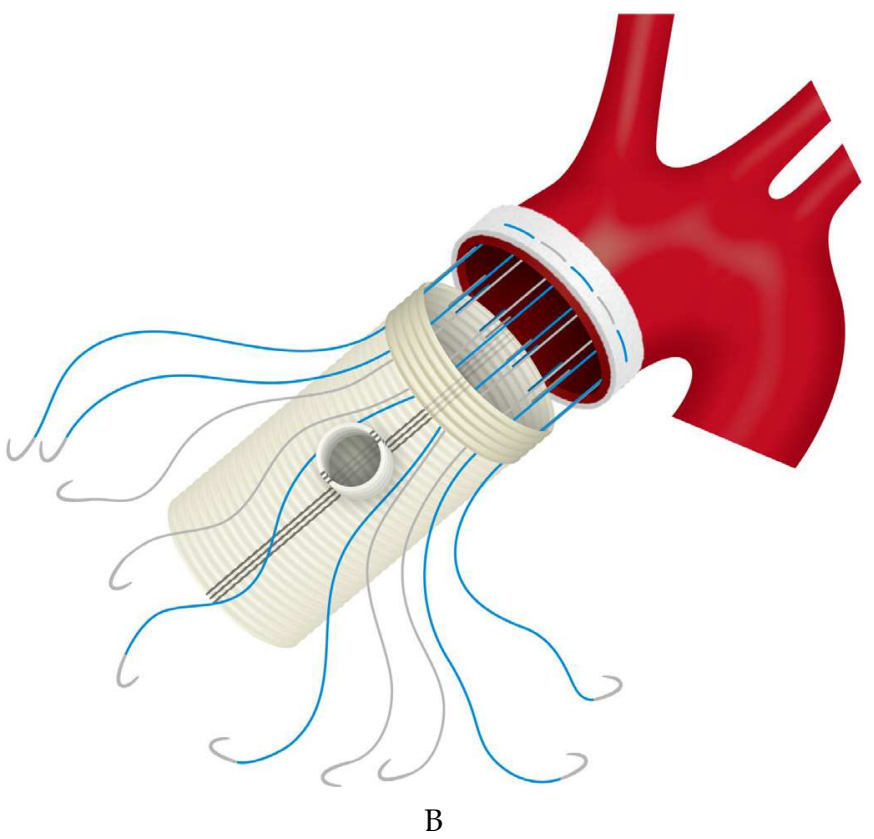



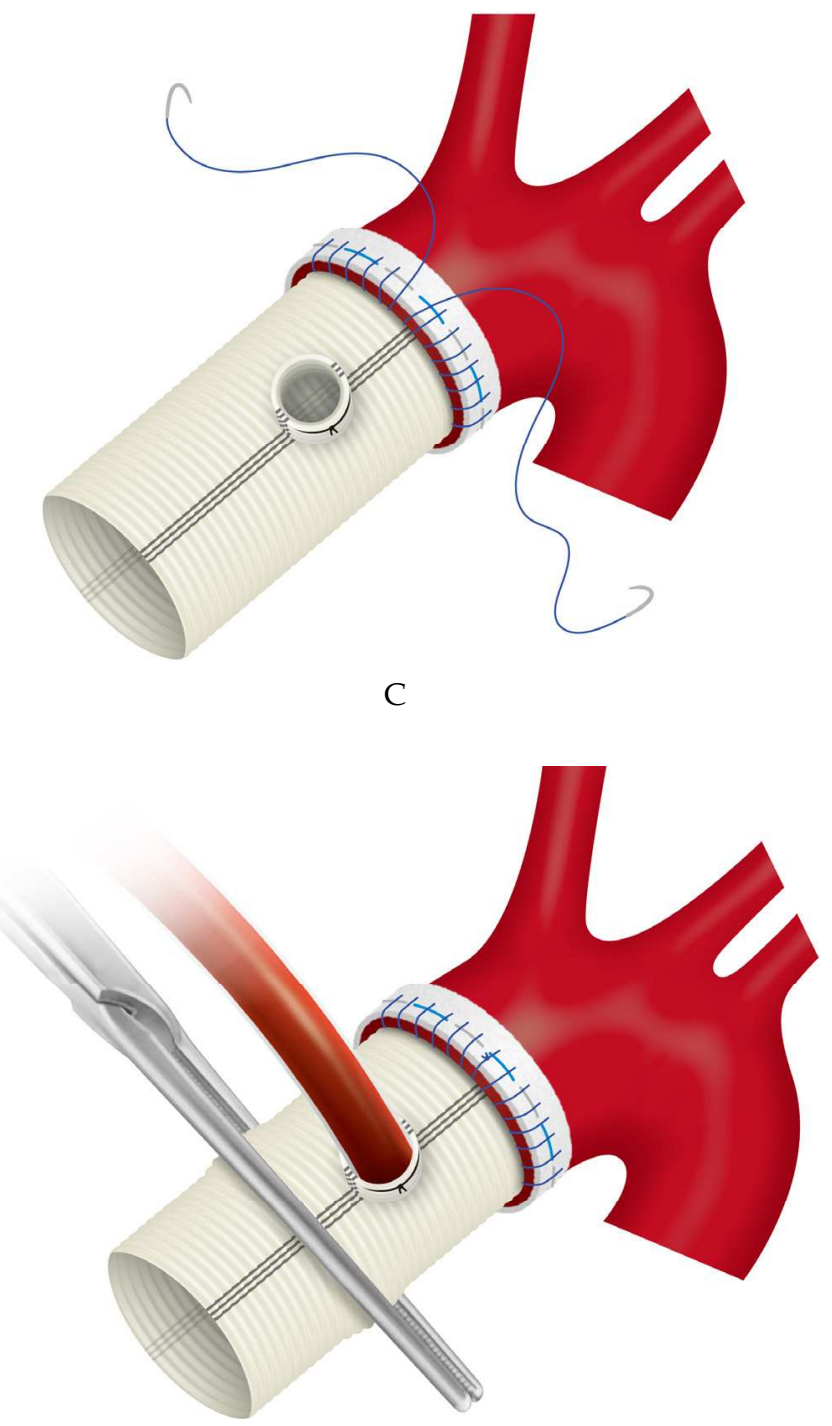

$\mathrm{D}$

Fig. 5. 5A. A Dacron graft with one side branch was sewn to the distal end of the ascending aorta with 4-0 polyfilament braided sutures in a horizontal mattress fashion. 5B. The distal end of the Dacron graft $(1 \mathrm{~cm}$ in length) was gently fixed in an inverted form. $5 \mathrm{C}$. The anastomosis was reinforced with additional 3-0 polypropylene over-and-over suture. 5D. After completion of the distal anastomosis, cerebral perfusion was withdrawn, and antegrade systemic perfusion was started via the side branch of the Dacron graft. (Hirota et al.) 
The proximal anastomosis was completed by single 3-0 polypropylene running sutures. Firstly, the proximal end of the graft was sewn to the posterior wall of the proximal aorta with 3-0 polypropylene running suture. Then, both ends of the suture were tied with other 3-0 polypropylene sutures to avoid relaxation of the posterior anastomosis. Thus, the posterior wall of the graft was fixed in an inverted form (Fig. 6A). Secondly, one stay suture was placed at the toe for easy adjustment (Fig. 6B). Thirdly, the anterior wall of the graft was sewn to the proximal aorta with 3-0 polypropylene running sutures from both ends (Fig. 6C).

\subsubsection{Concomitant procedure}

In combined coronary artery bypass grafting (CABG) and AVR procedures, distal anastomoses were completed without crossclamping during cooling. For beating CABG procedures, a heart retracting system with the Tentacles Heart Positioner (Sumitomo Bakelite, Tokyo, Japan), which provides excellent exposure of target coronary arteries ${ }^{18)}$, is usually used. Proximal anastomoses were performed during single crossclamping after AVR.

In combined mitral valve surgery and AVR, mitral valve plasty (MVP) or mitral valve replacement (MVR) was performed prior to AVR. For patients not requiring ascending aorta replacement, the ascending aorta was crossclamped after brief circulatory arrest. Subsequently, mitral valve surgery was initiated prior to AVR. For patients with ascending aorta replacement, the distal end of the ascending aorta was firstly sewn to a Dacron graft with one side branch during circulatory arrest (Fig. 6A). After the distal anastomosis, systemic and cerebral perfusion was antegradely maintained via the side branch of the graft (Fig. 6B). Then, mitral valve surgery was initiated prior to AVR. When the left side Maze procedure was indicated, it was performed via the right-sided left atriotomy during mitral valve surgery. After completion of mitral valve surgery, AVR was started as described above. Subsequently, the left atrium was closed and the proximal anastomosis of the ascending aorta was performed (Fig. 6C). Finally, the right side Maze procedure and/or tricuspid valve surgery was performed through the right atriotomy.

\section{Results}

Of a total of 705 patients having AVR, 46 patients $(11 \%)$ with a calcified ascending aorta required brief circulatory arrest for internal inspection of the ascending aorta. Of these 46 patients, 42 (92\%) underwent simple AVR after safe aortic crossclamping. The duration of circulatory arrest was less than $1 \mathrm{~min}$ in 40 patients and the longest duration was 3 min (mean $0.9 \pm 0.6 \mathrm{~min})$. In 3 patients $(7 \%)$, AVR plus ascending aorta replacement was performed due to an unclampable ascending aorta during circulatory arrest at moderate hypothermia $\left(28^{\circ} \mathrm{C}\right)$. For 1 patient (1\%), the Bentall operation was done due to a dilated sinus of Valsalva.

In this series, patients had AVR with a bioprosthetic $(n=31 ; 67 \%)$ or a mechanical valve $(n=15 ; 33 \%)$. Twenty-two patients $(48 \%)$ had Carpentier-Edwards pericardial valves (Edwards Life Science Corporation, Irvine, CA, USA), 9 patients (20\%) had CarboMedics Top Hat mechanical valves (CarboMedics, Inc., Austin, TX, USA), 6 patients (13\%) had Sorin Bicarbon-Slim mechanical valves (Sorin Biomedica, Saluggia, Italy), 5 patients $(11 \%)$ had Medtronic Mosaic valves (Medtronic Inc., Minneapolis, MN, USA), 1 patient had a Prima Plus Stentless valve (Edwards Life Science Corporation), and 1 patient had a Medtronic Freestyle valve (Medtronic Inc.). 


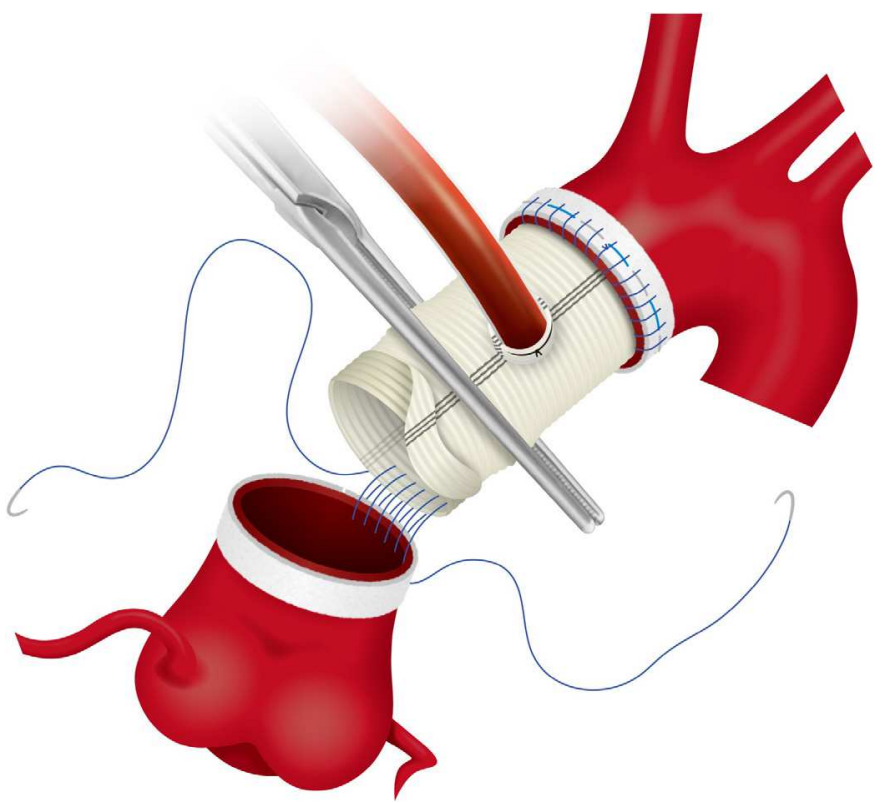

A

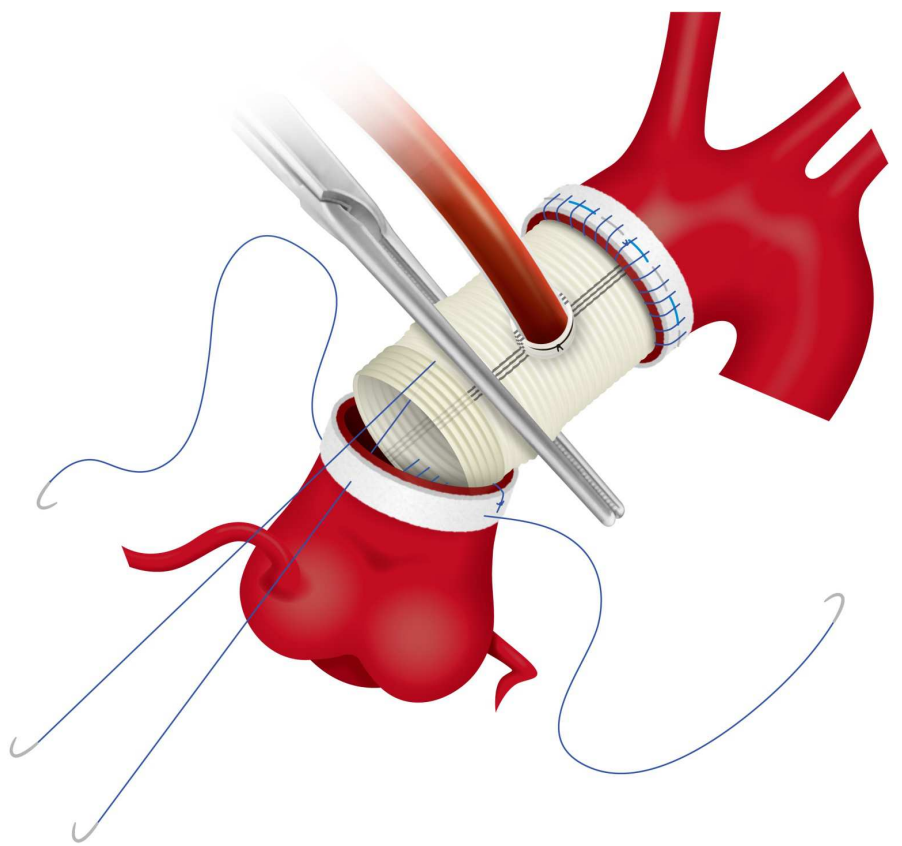

B 


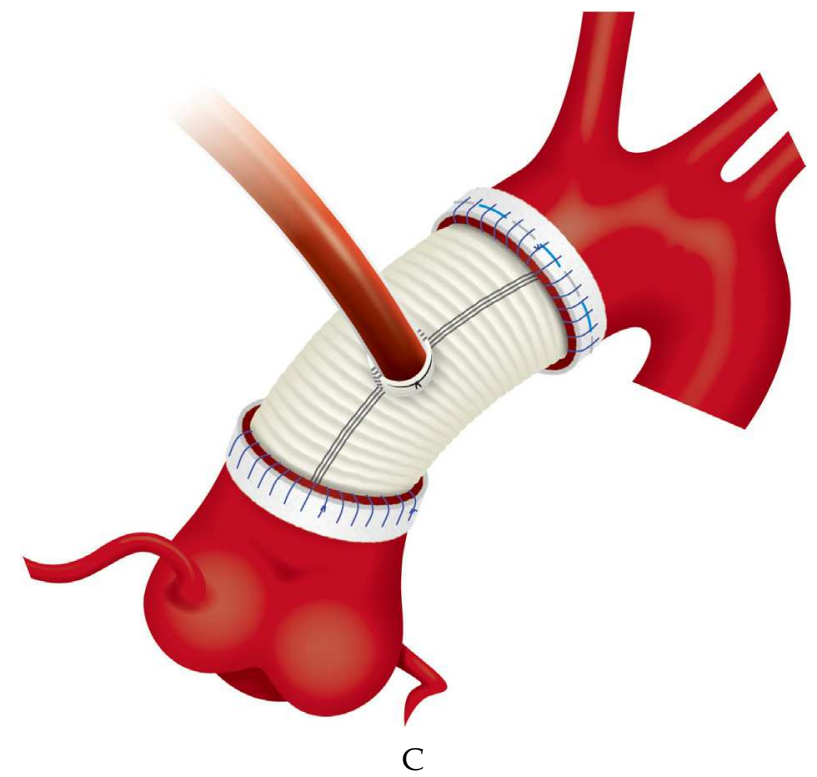

Fig. 6. 6A. The proximal end of the graft was sewn to the posterior wall of the proximal aorta with 3-0 polypropylene running suture. 6B. Both ends of the suture were tied with other 3-0 polypropylene sutures to avoid relaxation of the posterior anastomosis. Thus, the posterior wall of the graft was fixed in an inverted form. One stay suture was placed at the toe for easy adjustment. $6 \mathrm{C}$. The anterior wall of the graft was sewn to the proximal aorta with 3-0 polypropylene running sutures from both ends. (Hirota et al.)

Twenty-seven patients (59\%) had concomitant procedures including CABG $(n=18)$, MVR $(n=6)$, MVP $(n=2)$, the Maze procedure $(n=4)$, and tricuspid annuloplasty $(n=3)$. No intraaortic balloon pumping was required postoperatively. Aortic crossclamping time was $76 \pm 18$ min. CPB time was $148 \pm 29 \mathrm{~min}$. Operative time was $330 \pm 69 \mathrm{~min}$. The hospital mortality was $2.2 \%$ (1 of 46). One patient died of gastrointestinal bleeding. There was no cardiogenic death in this series. The postoperative morbidity was $2.2 \%$ ( 1 of 46 ). Cerebrovascular accident occurred in one patient.

\section{Discussion}

Patients with AS and a calcified ascending aorta were treated with meticulous techniques. Careful maneuvers for calcified lesions would reduce atheroembolic complications, contributing to better surgical outcomes.

The surgical challenge of dealing with patients with AS and calcified ascending aorta started in the 1980s ${ }^{10,11)}$. With advances in medical technology, the surgical strategy has been modified in various ways. Theoretically, the simplest approach is supposed to be AVR without aortic crossclamping during $\mathrm{HCA}^{10-12)}$. Although the no-touch technique to the calcified aorta effectively reduces the surgical risk of atheroembolic events, prolonged HCA time is a risk for stroke ${ }^{19}$. As a different strategy to facilitate AVR, endarterectomy during HCA has been reported to avoid embolic events ${ }^{13,20)}$. No patients with postoperative stroke 
suggested a good early result, but there were no follow-up data relating to the long-term risks of aortic dissection or dilatation. Although HCA provides simple strategies for patients with AS and a calcified ascending aorta, technical modifications are needed to render the procedure less invasive.

Aortic crossclamping is one of the most technically difficult aspects for patients with a calcified ascending aorta. The release of aortic crossclamping is closely associated with embolic events during cardiac surgery ${ }^{9}$. As an alternative for aortic crossclamping, a method of internal occlusion of the ascending aorta was reported; i.e., endoaortic balloon occlusion 15$)$. According to that report, a Foley catheter was directly introduced via the usual aortotomy during a brief period of circulatory arrest at a nasopharyngeal temperature of $25^{\circ} \mathrm{C}$. Although the advantages of endoaortic balloon occlusion include easy preparation and less invasive technique, a retrospective analysis demonstrated that it was frequently ineffective and was associated with a significantly higher risk of in-hospital death and a numerically higher risk of stroke21).

We used brief circulatory arrest less than $1 \mathrm{~min}$ in most cases at moderate hypothermia $\left(28^{\circ} \mathrm{C}\right)$ for internal inspection of calcified ascending aorta. The extent and severity of calcification is directly observed, and the firmness of the calcified ascending aorta is also palpable without wall stress caused by afterload. Thus, in this situation, it is easy to determine whether the calcified ascending aorta is clampable. When the calcified ascending aorta is clampable, simple AVR followed by aortic crossclamping is planned as a less invasive operation. However, ascending aorta replacement would be performed for patients with an unclampable calcified ascending aorta. At moderate hypothermia $\left(28^{\circ} \mathrm{C}\right)$, simple AVR could be converted into ascending aorta replacement under circulatory arrest with selective cerebral perfusion. Thus, patients with AS and calcified ascending aorta are surgically repaired by our strategy without deep HCA.

A recent surgical report also demonstrated that short-term moderate hypothermic arrest is useful for safe aortic crossclamping after internal inspection of a bad ascending aorta22). Although this technique for safe crossclamping is almost the same as our strategy, all cases were treated with simple AVR followed by aortic crossclamping. The reason for this would include endarterectomy or debridement by the Cavitron ultrasonic surgical aspirator (CUSA) ${ }^{23)}$, which successfully achieves a safe aortic crossclamping site. Therefore, circulatory arrest time was slightly longer ( $3.4 \pm 1.5 \mathrm{~min}$ ) compared to ours (less than $1 \mathrm{~min}$ ). Although small calcific particles created by the CUSA are potential causes of postoperative stroke, all of them would be completely aspirated. As a result, the postoperative stroke rate remained low $(2.5 \%)$, with no mortality. For patients with a calcified ascending aorta, the CUSA would also be useful for removing calcific debris during AVR.

As one of the alternatives for open heart surgery, transcatheter valve implantation (TAVI) had been newly developed for symptomatic patients at high risk or with contraindications for surgery24). A calcified ascending aorta would be a good indication for TAVI. Successful TAVI dramatically alleviates severe symptoms with a minimally-invasive method. However, TAVI involves major complications such as paravalvular leakage, valve malposition, coronary occlusion, annulus and aortic root rupture, atrioventricular block, and cerebrovascular events25). The 30-day all-cause mortality rate with the CoreValve Revalving System (Medtronic Inc.) ranges from 5.5\% to 15.5\%, while that with the Edwards Sapien prosthesis (Edwards Life Science Corporation) ranges from $6.3 \%$ to $10.3 \% 25$ ). Although the incidence of persistent neurological impairment was low (less than approximately $5 \%$ ), the incidence of clinically silent peri-interventricular cerebral embolic lesions after TAVI was 
high ${ }^{25,26)}$. The results of TAVI would be improved by further development of medical devices, but current results are not far superior to our surgical outcomes. Accordingly, there is no established treatment for AS and calcified ascending aorta at present.

In the future, prevalence of calcified lesions, including AS and calcified ascending aorta, is likely to increase as the average lifespan of populations increases. With the advances in medical technologies, new therapeutic technologies, such as TAVI, will be developed for safer strategies and to minimize invasiveness. However, TAVI is not the optimal treatment for all patients with AS, including patients requiring concomitant procedures such as CABG and mitral valve surgery. For these patients, conventional open heart surgery would be one of the therapeutic choices. Additionally, state-of-the-art technologies will not be available worldwide. Thus, cardiac surgeons should continue to modify their strategies by meticulous techniques and share their strategies for better outcomes. Addressing this surgical challenge would result in resolution for many more high-risk patients with complex calcified lesions.

\section{Conclusion}

Technical modifications such as right axillary artery cannulation and brief circulatory arrest at moderate hypothermia are useful for patients with AS associated with a calcified ascending aorta. The operative design would be important to minimize the surgical risk for such high-risk patients.

\section{References}

[1] Carabello BA, Paulus WJ. Aortic stenosis. Lancet. 2009 14; 373: 956-66

[2] Stewart BF, Siscovick D, Lind BK, Gardin JM, Gottdiener JS, Smith VE, Kitzman DW, Otto CM. Clinical factors associated with calcific aortic valve disease. Cardiovascular Health Study. J Am Coll Cardiol. 1997; 29: 630-4

[3] Otto CM, Lind BK, Kitzman DW, Gersh BJ, Siscovick DS. Association of aortic-valve sclerosis with cardiovascular mortality and morbidity in the elderly. N Engl J Med. 1999; 34: 142-7

[4] Vahanian A, Baumgartner H, Bax J, Butchart E, Dion R, Filippatos G, Flachskampf F, Hall R, Iung B, Kasprzak J, Nataf P, Tornos P, Torracca L, Wenink A; Task Force on the Management of Valvular Health Disease of the European Society of Cardiology; ESC Committee for Practice Guidelines. Guidelines on the management of valvular disease: The Task Force on the Management of Valvular Heart Disease of the European Society of Cardiology. Eur Heart J. 2007; 28: 230-68

[5] Varadarajan P, Kapoor N, Bansal RC, Pai RG. Survival in elderly patients with severe aortic stenosis is dramatically improved by aortic valve replacement: Results from a cohort of 277 patients aged $>$ or $=80$ years. Euro J Cardiothorac Surg. 2006; 30: $722-7$

[6] Bonow RO, Carabello BA, Chatterjee K, de Leon AC Jr, Faxon DP, Freed MD, Gaasch WH, Lytle BW, Nishimura RA, O'Gara PT, O'Rourke RA, Otto CM, Shah PM, Shanewise JS; American College of Cardiology/American Heart Association Task Force on Practice Guidelines. 2008 focused update incorporated into the ACC/AHA 2006 guidelines for the management of patients with valvular heart disease: a report of the American College of Cardiology/American Heart Association Task Force on Practice Guidelines (Writing Committee to revise the 
1998 guidelines for the management of patients with valvular heart disease). Endorsed by the Society of Cardiovascular Anesthesiologists, Society for Cardiovascular Angiography and Interventions, and Society of Thoracic Surgeons. J Am Coll Cardiol. 2008; 52: e1-142

[7] van der Linden J, Hadjinikolaou L, Bergman P, Lindblom D. Postoperative stroke in cardiac surgery is related to the location and extent of atherosclerotic disease in the ascending aorta. J Am Coll Cardiol. 2001; 38: 131-5

[8] Gillinov AM, Lytle BW, Hoang V, Cosgrove DM, Banbury MK, McCarthy PM, Sabik JF, Pettersson GB, Smedira NG, Blackstone EH. The atherosclerotic aorta at aortic valve replacement: surgical strategies and results. J Thorac Cardiovasc Surg. 2000; 120: 957-63

[9] Barbut D, Hinton RB, Szatrowski TP, Hartman GS, Bruefach M, Williams-Russo P, Charlson E, Gold JP. Cerebral emboli detected during bypass surgery are associated with clamp removal. Stroke. 1994; 25: 2398-402

[10] Jacobowitz IJ, Rose DM, Shevede K, Cunningham JN. Use of profound hypothermia and circulatory arrest for the calcified aorta. Chest. 1984; 85: 288-9

[11] Coselli JS, Crawford ES. Aortic valve replacement in the patient with extensive calcification of the ascending aorta (the porcelain aorta). J Thorac Cardiovasc Surg. 1986; 91: 184-7

[12] Byrne JG, Aranki SF, Cohn LH. Aortic valve operations under deep hypothermic circulatory arrest for the porcelain aorta: "no-touch" technique. Ann Thorac Surg. 1998; 65: 1313-5

[13] Vogt PR, Hauser M, Schwarz U, Jenni R, Lachat ML, Zund G, Schupbach RW, Schmidlin D, Turina MI. Complete thromboendarterectomy of the calcified ascending aorta and aortic arch. Ann Thorac Surg. 1999; 67: 457-61

[14] Aranki SF, Nathan M, Shekar P, Couper G, Rizzo R, Cohn LH. Hypothermic circulatory arrest enables aortic valve replacement in patients with unclampable aorta. Ann Thorac Surg. 2005; 1679-86

[15] Cosgrove DM. Management of the calcified aorta: an alternative method of occlusion. Ann Thorac Surg. 1983; 36: 718-9

[16] Lockowandt U. Apicoaortic valved conduit: potential for progress? J Thorac Cardiovasc Surg. 2006; 132: 796-801

[17] Isomura T, Hisatomi K, Satoh T, Hayashida N, Aoyagi S. Axillary artery cannulation for cardiopulmonary bypass in the presence of diseased ascending aorta. Eur J Cardiothorac Surg. 1996; 10; 481

[18] Shimamura Y, Mochizuki Y, Yamada Y, Eda K, Shibasaki I, Inoue Y, Miyoshi S. Surgical technique of displacement and retraction of the heart with a pigtail shaped hook and Tentacles Heart Positioner. Kyobu Geka. 2007; 60: 547-9

[19] Svensson LG, Crawford ES, Hess KR, Coselli JS, Raskin S, Shenaq SA, Safi HJ. Deep hypothermia with circulatory arrest. Determinants of stroke and early mortality in 656 patients. J Thorac Cardiovac Surg. 1993; 106: 19-28

[20] Svensson LG, Sun J, Cruz HA, Shahian DM. Endarterectomy for calcified porcelain aorta associated with aortic valve stenosis. Ann Thorac Surg. 1996; 61: 149-52

[21] Zingone B, Gatti G, Rauber E, Pappalardo A, Benussi B, Dreas L. Surgical management of the atherosclerotic ascending aorta: is endoaortic balloon occlusion safe? Ann Thorac Surg. 2006; 82: 1709-4 
[22] Takami Y, Tajima K, Terazawa S, Okada N, Fujii K, Sakai Y. Safer aortic crossclamping during short-term moderate hypothermic circulatory arrest for cardiac surgery in patients with a bad ascending aorta. J Thorac Cardiovasc Surg. 2009; 137: 875-80

[23] Kellner HJ, Pracki P, Hildebrandt A, Binner C, Eisele G, Struck E. Aortic valve debridement by ultrasonic surgical aspirator in degenerative, aortic valve stenosis: follow-up with Doppler echocardiography. Eur J Cardiothorac Surg. 1996; 10; 498504

[24] Vahanian A, Alfirei O, Al-Attar N, Antunes M, Bax J, Cormier B, Cribier A, De Jaeqere P, Fournial G, Kappetein AP, Kovac J, Ludqate S, Maisano F, Moat N, Mohr F, Nataf P, Pierard L, Pomar JL, Schofer J, Tornos P, Tuzcu M, van Hout B, Von Seqesser LK, Walther T; European Association of Cardio-Thoracic Surgery; European Society of Cardiology; European Association of Percutaneous Cardiovascular Interventions. Transcatheter valve implantation for patients with aortic stenosis: a position statement from the European Association of CardioThoracic Surgery (EACTS) and the European Society of Cardiology (ESC), in collaboration with the European Association of Percutaneous Cardiovascular Interventions (EAPCI). Eur Heart J. 2008; 29: 1463-70

[25] Spaccarotella C, Mongiardo A, Indolfi C. Pathophysiology of aortic stenosis and approach to treatment with percutaneous valve implantation. Circ J. 24; 75: 11-19

[26] Ghanem A, Muller A, Nahle CP, Kocurek J, Werner N, Hammerstingl C, Schild HH, Schwab JO, Mellert F, Fimmers R, Nickenig G, Thomas D. Risk and fate of cerebral embolism after transfemoral aortic valve implantation: a prospective pilot study with diffusion-weighted magnetic resonance imaging. J Am Coll Cardiol. 2010; 55: 1427-32 


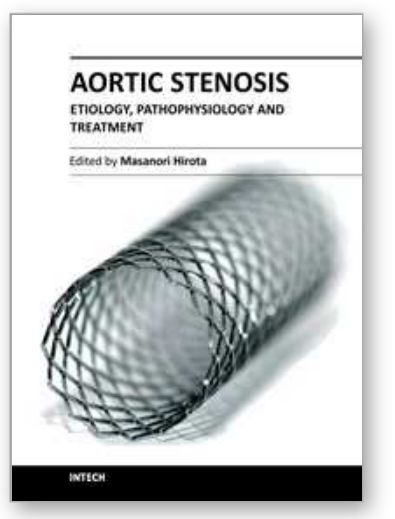

\author{
Aortic Stenosis - Etiology, Pathophysiology and Treatment \\ Edited by Dr. Masanori Hirota
}

ISBN 978-953-307-660-7

Hard cover, 254 pages

Publisher InTech

Published online 10, October, 2011

Published in print edition October, 2011

Currently, aortic stenosis (AS) is the most prevalent valvular disease in developed countries. Pathological and molecular mechanisms of AS have been investigated in many aspects. And new therapeutic devices such as transcatheter aortic valve implantation have been developed as a less invasive treatment for high-risk patients. Due to advanced prevalent age of AS, further discovery and technology are required to treat elderly patients for longer life expectancy. This book is an effort to present an up-to-date account of existing knowledge, involving recent development in this field. Various opinion leaders described details of established knowledge or newly recognized advances associated with diagnosis, treatment and mechanism. Thus, this book will enable close intercommunication to another field and collaboration technology for new devices. We hope that it will be an important source, not only for clinicians, but also for general practitioners, contributing to development of better therapeutic adjuncts in the future.

\title{
How to reference
}

In order to correctly reference this scholarly work, feel free to copy and paste the following:

Masanori Hirota, Joji Hoshino, Yasuhisa Fukada, Shintaro Katahira, Taichi Kondo, Kenichi Muramatsu and Tadashi Isomura (2011). Technical Modifications for Patients with Aortic Stenosis and Calcified Ascending Aorta During Aortic Valve Replacement, Aortic Stenosis - Etiology, Pathophysiology and Treatment, Dr. Masanori Hirota (Ed.), ISBN: 978-953-307-660-7, InTech, Available from:

http://www.intechopen.com/books/aortic-stenosis-etiology-pathophysiology-and-treatment/technicalmodifications-for-patients-with-aortic-stenosis-and-calcified-ascending-aorta-during-aorti

\section{INTECH}

open science | open minds

\section{InTech Europe}

University Campus STeP Ri

Slavka Krautzeka 83/A

51000 Rijeka, Croatia

Phone: +385 (51) 770447

Fax: +385 (51) 686166

www.intechopen.com

\section{InTech China}

Unit 405, Office Block, Hotel Equatorial Shanghai

No.65, Yan An Road (West), Shanghai, 200040, China 中国上海市延安西路65号上海国际贵都大饭店办公楼 405 单元

Phone: +86-21-62489820

Fax: $+86-21-62489821$ 
(C) 2011 The Author(s). Licensee IntechOpen. This is an open access article distributed under the terms of the Creative Commons Attribution 3.0 License, which permits unrestricted use, distribution, and reproduction in any medium, provided the original work is properly cited. 